\title{
LINGUÍSTICA CONTEMPORÂNEA NA RÚSSIA: FERRAMENTAS PARA UM DIÁLOGO INTER BRICS
}

\author{
Elena S. Nikolaeva \\ St.-Petersburg State University, \\ Faculty of Philology, Department of Romanic Languages, \\ $\mathrm{PhD}$ (Cand. of Sc.), Associate Professor (docent) \\ e.s.nikolaeva@spbu.ru
}

Resumo: A ciência é uma das características definidoras da cultura moderna e talvez seu componente mais dinâmico. Hoje é impossível discutir problemas sociais, culturais, antropológicos sem levar em conta o desenvolvimento do pensamento científico. Ela está cada vez mais tentando integrar organicamente as conquistas científicas e tecnológicas ao mundo, usando seus métodos e dados de pesquisas científicas para elaborar planos de grande escala para o desenvolvimento social e econômico. O desenvolvimento dos conhecimentos científicos é amplamente determinado pelo estado da linguística - a ciência da linguagem, com a qual os fundamentos do conhecimento científico são formulados e transmitidos. Os processos de globalização que ocorrem no mundo moderno têm impacto no setor educacional. Hoje estamos testemunhando o surgimento de uma economia global do conhecimento, o que obriga a desenvolver ativamente a cooperação acadêmica internacional. Desde os primeiros dias de sua existência, o BRICS começou a desenvolver a cooperação acadêmica. Só a internacionalização da educação é capaz de proporcionar conhecimentos relevantes e a mais ampla compreensão possível do mundo e da interação das culturas que o constituem. A linguística russa que, por um lado, se desenvolve em linha com as tendências científicas modernas, por outro, devido às peculiaridades do desenvolvimento histórico, possui muitas características específicas, pode dar uma contribuição significativa para esse processo.

Palavras-chave: linguística russa, ensino de idiomas, cooperação acadêmica, BRICS.

\section{CONTEMPORARY LANGUAGE IN RUSSIA: TOOLS FOR AN INTER BRICS DIALOGUE}

\begin{abstract}
Science is one of the defining characteristics of modern culture and perhaps its most dynamic component. Today, it is impossible to discuss social, cultural, anthropological problems without taking into account the development of scientific thought. It is increasingly trying to organically integrate scientific and technological achievements into the world, using its methods and data from scientific research to develop large-scale plans for
\end{abstract}


social and economic development. The development of scientific knowledge is largely determined by the state of linguistics - the science of language, with which the foundations of scientific knowledge are formulated and transmitted. The globalization processes that take place in the modern world have an impact on the educational sector. Today we are witnessing the emergence of a global knowledge economy, which requires us to actively develop international academic cooperation. From the first days of its existence, BRICS began to develop academic cooperation. Only the internationalization of education is capable of providing relevant knowledge and the widest possible understanding of the world and the interaction of the cultures that constitute it. Russian linguistics, which, on the one hand, develops in line with modern scientific trends, on the other, due to the peculiarities of historical development, has many specific characteristics, can make a significant contribution to this process.

Linguística na Rússia apesar de ter desenvolvido nos quadros da ciência filológica internacional, teve alguns particularidades específicas devido aos fatores históricos, políticos e sociais que influenciaram muito os processos científicos, escolas e orientações linguísticas, metodologia e base científica que a linguística russa nos oferece hoje. Precisaremos fazer uma pequena excursão pela história para mostrar as peculiaridades da formação de certas tendências e direções da linguística russa, a formação e o desenvolvimento de escolas de pesquisa e, a esse respeito, destacar as áreas que possam ser de interesse dos estudantes estrangeiros, em particular dos países do BRICS.

Nas primeiras décadas do século XX a Rússia ocupava posiçõeschave em quase todos os campos científicos promissores que moldaram o mundo da ciência e tecnologia naquela época. A ascensão da ciência, educação e indústria russas foi interrompida pela revolução soviética de 1917. Começou a guerra civil, a fome, a repressão às “classes exploradoras", nas quais também se inscreveram cientistas, apesar de a maioria dos dirigentes revolucionários possuírem formação universitária. Foi imposta uma doutrina que apenas os cientistas vindos da classe operária correspondiam ao partidarismo proletário. Os outro mereciam desconfiança profissional e expulsão da comunidade científica. Muitos cientistas e engenheiros extraordinários 
morreram de fome e epidemias, foram assassinados, expulsos do país ou se suicidaram.

O resultado daquela política foi a emigração em massa de representantes da cultura russa. É importante notar, porém, que a partir de certo ponto, aproximadamente a partir do final de 1918, o governo soviético e o próprio Lenin passaram a defender os cientistas que se submetiam ao novo governo. O curto apogeu da década de 1920 terminou após o anúncio da "grande virada" de 1928-1931. Uma onda de repressão contra cientistas varreu o país.

Em 1936 começou uma violenta campanha de repressão política, o Grande Expurgo, feito pelo Secretário Geral do Partido Comunista Josef Stalin que liquidou, entre outros, inúmeros cientistas, considerando-os todos "inimigos do povo". O periodo da ditadura de Estaline (finais dos anos 20-50 do séc. XX) não pode ser esquecida por ter afetado muito a ciencia daquela época o que tinha levado muito para traz o desenvolvimento ciéntifico. O regime controlou a ciência e impunha as doutrinas a serem seguidas. Expurgos levaram à morte de cientistas proeminentes e ao esquecimento das suas obras.

Como um dos componentes mais importantes da política do governo soviético foi proclamada a revolução cultural. Em última análise, perseguiu duas tarefas principais: familiarizar a população em geral com a cultura e mostrar as vantagens do novo sistema. O critério ideológico passou a ser o principal na avaliação da qualidade de qualquer "produto" da intelectualidade criativa. O sistema educacional, as ciências sociais, a literatura, a arte e o teatro se tornaram instrumentos da influência educacional do governo soviético. A cultura ocidental foi declarada atolada em declínio e degeneração. Não apenas um soviético nada tinha a aprender no Ocidente, mas, ao contrário, os ocidentais progressistas deveriam aprender com o povo soviético. Essa abordagem também afetou o trabalho científico. As referências às obras de autores estrangeiros modernos foram consideradas uma manifestação inaceitável de "rastejar". A campanha manifestou-se mais vividamente nas ciências humanas (1948-1954). É evidente que tal ideologia jogou a ciência para trás, porque no mundo moderno um cientista não pode 
criar algo, estando afastado das conquistas científicas internacionais, da informação, da base empírica.

Para se ter uma pequena ideia do tamanho dessa tragédia para a ciência, basta mencionar os dois Casos fabricados contra estudiosos, que praticamente decapitaram a ciência soviética. Caso Acadêmico - um caso criminal fabricado contra um grupo de cientistas da Academia de Ciências em 1929-1931 em Leningrado (hoje São Petersburgo), onde a Academia de Ciências estava localizada até 1934. No total, em dezembro de 1929 - dezembro de 1930, mais de 100 pessoas foram presas no "Caso Acadêmico" (principalmente especialistas em humanidades). O outro entrou na história como o Caso dos estudiosos orientais. A perseguição começou em 1930, a primeira vítima foi o indólogo Alexander Merwart, que foi o primeiro estudioso russo a visitar as regiões de difícil acesso da Índia e do Ceilão e a organizar o ensino da língua tamil na URSS. Junto com outros pesquisadores importantes, ele foi processado por cooperação com a inteligência ocidental - suspeitas foram levantadas por sua origem alemã e sua longa estadia no exterior. Em 1937, começaram as repressões massivas. Dezenas de orientalistas foram presos e muitos executados. Hoje, o que aconteceu com os estudos orientais na década de 1930 é reconhecido como um desastre. Não uma grande perda, mas uma catástrofe, porque quase toda a geração mais jovem de orientais foi destruída - a camada que personificava a continuidade na ciência e sem a qual ela não poderia se desenvolver tão fecundamente.

Outro fator muito importante que determinou uma certa especificidade da ciência russa em geral e da linguística em particular foi o período soviético mais tardio, o de "Cortina de Ferro" no período da Guerra Fria quando os contactos com o mundo exterior para cidadãos soviéticos foram minimizados, até quase impossíveis, assim como o intercâmbio de idéias sem o qual o desenvolvimento científico é impossível. Esse isolamento pode servir como uma explicação para algumas tendências no desenvolvimento da filologia, que estamos observando agora.

Tais pré-requisitos históricos determinaram bastante o pósdesenvolvimento da linguística russa, apesar de ter mudada a época (Comrie Bernard \& Gerald Stone \& Maria Polinsky 1996). 
Se para a linguística do período pré-revolucionario (revolução de 1917) foi típica a abordagem filosófica para esta ciência, uma característica do período de após a revolução veio a ser a intenção de obter benefícios práticos diretos de qualquer pesquisa (BEREZIN, 2003, p. 48). Diante dos problemas de um país grande e devastado a linguística devia resolver muitas tarefas: a criação de um sistema de escrita para muitas línguas não escritas e essencialmente inexploradas, a disseminação da língua literária entre os trabalhadores e a metodologia de ensino de línguas europeias estrangeiras, amplamente introduzida às massas, e outras. Perdendo algo no sentido teórico e filosófico, a linguística de então foi predestinada para resolver problemas pragmáticos, formando assim a metodologia muito eficaz para oferecer hoje em dia.

Como o resultado a Russia tem uma escola muito forte de ensino prático de idiomas. Desenvolvendo-se no espaço fechado de "Cortina de Ferro" no período da Guerra Fria quando sem possibilidade para pessoas de viajarem pelo mundo e estudarem e trabalharem no estrangeiro, foi desenvolvido o sistema de ensinar idiomas que se baseava em textos, gramática, leitura dos livros clássicos. Asssim chamada forma tradicional de aprender uma língua estrangeira, o método de estudo de tradução gramatical com base na compreensão da língua como um sistema e abordagem cognitiva da aprendizagem. Este método foi amplamente utilizado na Europa para ensinar grego e latim. A análise de texto desempenha um papel importante no processo de aprendizagem e tradução, bem como na memorização de material linguístico. A escola gramatical enfocada na estrutura sintática da frase adquiriu o seu futuro desenvolvimento. Atualmente, quando existem muitos métodos comunicativos, este sistema continua a funcionar e oferece muitas vantagens.

Abertas as fronteiras com países estrangeiros, surgiu uma necessidade de realizar e manter os contactos em várias áreas da vida moderna, o que levou a mudanças em métodos de ensino de línguas estrangeiras. A primeira linha em popularidade de técnicas é ativamente sustentada por uma abordagem comunicativa que, como o próprio nome sugere, centra-se na prática da comunicação. 
Há quem ache que uma abordagem comunicativa para o ensino de línguas estrangeiras surgiu na década de 70 do século XX no Reino Unido, em conexão com o avanço de um novo objetivo de aprendizagem - uso do idioma como meio de comunicação. Mas na Rússia este método nasceu e começou a ser desenvolvido pelo menos 10 anos antes. Vamos citar os autores publicados na década de anos 1960 de trabalho: E.P. Shubin, P. B. Gurvich, I.L. Bim, V.L. Skalkin, B.V. Belyaev, A.A. Leontiev, A.P. Starkov, E.I. Passov e outros, direta ou indiretamente contribuíram para o fato de que nos anos 1970 a direção comunicativa tomou forma muito clara (ZHARKOVA, 2014, p. 70).

Combinando todas as direções metodológicas contemporâneas e tradicionais, as Faculdades de Letras russas oferece o ensino da língua russa, que tem muita demanda, de alta qualidade e pode garantir aos estudantes estrangeiros o bom domínio do idioma, aproximando o processo de aprendizagem ao processo real de comunicação e ao mesmo tempo dando amplos conhecimentos da cultura e história russa.

Uma característica da linguística do século XX foi a elaboração da teoria do diálogo. Na Rússia, os estudos sobre o diálogo se desenvolvem em vários centros de pesquisa. Em razão das circunstâncias nas quais a teoria do diálogo apareceu na Rússia, a maioria dos autores ocidentais faz referência a M. Bakhtin e aos seus trabalhos, entre os quais citam seus dois livros sobre Dostoievski (1929 e 1963), as obras dos anos 1960-70 e o livro Marxismo e filosofia da linguagem, publicado sob o nome de Voloshinov em 1929. Este livro é considerado um dos primeiros em que os princípios do dialogismo foram formulados por Bakhtin (Shulezhkova, 2006).

A escola linguística russa é famosa também por tais ramos como lexicologia e fraseologia sendo os cientistas russos descobridores nesta área. A lexicologia é um ramo da linguística que tem por objetivo o estudo científico de uma grande quantidade de palavras de um determinado idioma - léxico sob diversos aspectos. Para isso, ela procura determinar a origem, a forma e o significado das palavras que constituem o acervo de palavras de um idioma, bem como o seu uso na comunidade dos falantes. Assim, por meio da lexicologia torna-se possível observar e descrever cientificamente as unidades léxicas de uma comunidade linguística. 
A palavra como objeto da linguística sempre atraiu a atenção dos linguistas russos, que abordaram sua análise por vários ângulos. Resumindo a experiência de estudar a palavra, os linguistas russos lançaram as bases da lexicologia como um ramo independente da linguística. É curioso a esse respeito o reconhecimento do cientista estadunidense Uriel Weinreich: "Para um linguista americano, o mais surpreendente sobre a lexicologia soviética é que ela existe. Não há disciplina correspondente em linguística da Europa Ocidental ou americana " (Uriel Weinreich, 1964). Ele ainda observa que em livros bem conhecidos, a lexicologia nem mesmo é mencionada, ao contrário dos livros soviéticos, onde a lexicologia ocupa o mesmo lugar que a gramática e a fonética.

Os estudos sobre palavras, idiomas, provérbios, sentidos figurados das palavras, incluindo a comparação dos idiomas sempre provocam muito interesse dos estudantes. Outras áreas que também se atêm aos estudos do léxico são: a lexicografia, ciência instrumental que tem como finalidade a elaboração ou compilação de dicionários. E a terminologia, ciência responsável pelo estudo de termos de áreas específicas, ou seja, de vocabulários especializados.

Para quem tiver o interesse teórico pelas línguas, pode ser oferecido um vasto leque de temas de pesquisas, se baseando em realizações da linguística tradicional, estrutural e generativa, bem como os dados de muitos nichos semelhantes e usados em todos os tipos de aplicações e experimentos: neurolinguística, etnolinguística, estilística, linguística do texto, a teoria dos atos de fala, discurso linguístico, linguística cognitiva, etc.

Uma das tendências da linguística moderna é a sua expansão, que se manifesta no surgimento de novas escolas linguísticas e direções que consideram problemas de novas posições, inventar novos métodos e técnicas de análise, no descobrir novas facetas do objeto de pesquisa da linguagem, em integração linguística com outras ciências. Como resultado da expansão da linguística formaram-se ciências interdisciplinares, ocupando uma intermediária posição entre as esferas humanitária e não humanitária do conhecimento: linguística matemática, linguística de engenharia, linguofolclorística, linguopoética, linguoculturologia, sociolinguística, linguística cognitiva, psicolinguística, etnolinguística, etc. Mas um princípio 
da linguística moderna é a explantaridade, ou seja, o caráter explicativo. Convém lembrar que o estabelecimento das relações de causa e efeito, o desejo não só de descrever, mas também de explicar fatos linguísticos sempre foi o ponto mais forte da escola russa de linguística, enquanto muitos estudiosos estrangeiros (por exemplo, os primeiros gramáticos do século 19 e os estruturalistas da primeira metade do século $\mathrm{XX}$ ) acreditavam que o trabalho do linguista era afirmar o que é, e não explicar. Aí vem a outra caraterística da linguística moderna: através de links com outras ciências a linguística explica a pessoa que é um falante nativo e o mundo, onde o homem vive (Amirova \& Ol'khovikov \& Rozhdestvenskiy 2007).

Estas áreas são muito promissoras e podiam ser interessantes para os estudantes de outros países que quiserem estudar nas universidades da Rússia. O curso que sempre provoca interesse é o da sociolinguística que estuda a relação entre a língua e a sociedade. O principal problema teórico geral da sociolinguística é o estudo da natureza da linguagem como um fenômeno social, a conexão da linguagem com a sociedade, seu lugar e papel no desenvolvimento social - inclui muitas questões mais particulares e específicas que são tratadas individualmente, campos científicos especiais (por exemplo, etnolinguística lida com questões da relação entre língua e etnia; interlinguística explora questões sobre como organizar uma comunicação eficaz numa comunidade multilingue e as perspectivas de futuro da língua humana). O problema de "Língua e Sociedade" é amplo e multifacetado. Inclui muitas perguntas, mas entre elas as mais significativas, a saber, a natureza social da língua, condicionamento social do desenvolvimento da linguagem, formas da comunidade histórica do povo (história da língua e história do povo). Durante quase setenta anos da existência desta ciência os pesquisadores russos acumularam uma grande experiência (KOLESOV, 2003, p. 168). A tarefa de esclarecimento do papel dos fatores sociais no desenvolvimento da linguagem, estudo da diferenciação social da língua e a relação entre a língua e a sociedade em países de diferentes culturas e níveis de desenvolvimento pode apresentar o vasto campo para pesquisas especialmente para países com vários estratos sociais da população (como países BRICS). 
A natureza complexa da relação entre linguagem e etnia determinou atenção dos pesquisadores a este problema, o que levou ao surgimento de um ramo especial da ciência - etnolinguística, que estuda interação de fatores linguísticos e étnicos (VINOGRADOV, 2005, p. 235). Sendo a Rússia um país multinacional e tomando em conta que desde os primeiros anos da revolução soviética surgiu uma necessidade de criação de um sistema de escrita para muitas línguas não escritas e essencialmente inexploradas, especialistas russos acumularam enorme experiência prática e teórica nesta área.

Outro ramo atual é linguoecologia, ciência que estuda as condições sócio-políticas, socioeconômicas e linguodidáticas, proteção, revivificação e desenvolvimento de linguagens. A linguoecologia está intimamente relacionada com história, etnografia, jurisprudência e linguística propriamente dita.

Campo relativamente novo da ciência - linguística cultural. É uma disciplina científica complexa que estuda a relação e a influência mútua da cultura e da língua em seu funcionamento e refletindo este processo como uma estrutura integral na unidade de conteúdo linguístico e não linguístico (cultural).

Também as universidades da Rússia podem oferecer uma possibilidade de adquirir conhecimentos em áreas que se tem desenvolvido rápido: a psicolinguística que é um ramo da linguística que estuda a linguagem como o fenômeno da psique. Esta área trata de questões de aprendizagem, interação de linguagem, pensamento e consciência. Esta é uma ciência complexa, que pertence às disciplinas linguísticas, pois estuda linguagem, e às disciplinas psicológicas, uma vez que a estudam em um certo aspecto - como um fenômeno mental.

A neurolinguística é uma ciência que estuda os mecanismos cerebrais da fala, atividade em condições normais e com lesões cerebrais locais.

A linguística cognitiva é uma direção da linguística que explora os problemas da relação entre linguagem e consciência, o papel da linguagem em conceituação e categorização do mundo, nos processos cognitivos e 
resumindo a experiência humana, ligando ao indivíduo cognitivo habilidades humanas com a linguagem e as formas de sua interação. Esta área é muito promissora no mundo moderno. Além do valor teórico, pode permitir resolver muitos problemas práticos relacionados com a comunicação das pessoas em várias esferas da sua atividade.

Não provoca nenhuma dúvida a perspetiva de aplicação dos conhecimentos que oferecem o curso da linguística computacional. Muitos programas de computador, associados ao funcionamento da linguagem, usam algoritmos baseados em dados sobre a frequência de uso de fonemas, morfemas, unidades lexicais e construções sintáticas.

A linguística funcional é uma das áreas da moderna linguística, que é caracterizada pela atenção predominante para o funcionamento da linguagem como meio de comunicação.

Na Rússia existe uma tradição bastante longa de estudos e de ensino de todas as línguas do mundo, não sendo português uma excepção. Os Estudos Luso-Brasileiros são um campo de estudo interdisciplinar, que tem como objeto o estudo de vários aspectos da língua portuguesa e suas variantes, bem como da história e cultura de Portugal, do Brasil e de outros países de língua portuguesa.

O primeiro contacto do público com a cultura portuguesa ocorreu na Rússia nos séculos XVIII e XIX, graças às traduções de Lomonosov, Sumarokov, Pushkin, Zhukovsky e outros. No entanto, quase cem anos se passaram até aparecer o primeiro estudo - um artigo de M.V. Watson, publicado em 1890 sobre a literatura portuguesa. Em 1962 foi um ano chave na história dos estudos luso-brasileiros na Rússia. A sucursal espanhola do Departamento de Filologia Românica da Universidade de Leningrado (hoje São Petersburgo), por iniciativa da Profa. Dra. O.K. Vasilyeva-Shvede, foi transformada na sucursal hispano-portuguesa, a primeira da URSS a formar especialistas em língua e literatura portuguesas. Na origem deste departamento também estiveram os professores E. G. Golubeva e A. M. Gakh (Dicionário Internacional da Arte, da Literatura e da Cultura Contemporânea da Lusofonia, 2006, p. 46), o primeiro falante nativo e "pioneiro" da língua portuguesa, brasileiro de nacionalidade, que encheu com alma gaúcha as aulas acadêmicas no sombrio norte da Rússia. Na década de 1990, surgiram vários 
centros interdisciplinares, incluindo o Centro de Estudos Luso-Brasileiros da Universidade de São Petersburgo que realizou uma série de conferências científicas internacionais com os especialistas de Portugal, do Brasil, de Angola e outros (Mir Luzofonii, 2001). Esta cooperação continua até hoje, mantendo os contactos científicos com muitas Universidades, incluindo as brasileiras de São Paulo, da Bahia, de Santa Catarina e outras.

Outros focos dos Estudos Luso-Brasileiros são a Universidade Pedagógica em São Petersburgo e as Universidades de Moscou.

Mais uma escola científica - a de estudos orientais (chinês, hindi) enraizada em tempos mais distantes goza de reconhecimento justo e prepara os especialistas do nível muito alto. Os professores podem prestar ajuda aos estudantes estrangeiros para realizarem pesquisas comparativas, etnolinguísticas, de tradução, de estudos culturais.

Esperamos sinceramente que, no âmbito da cooperação entre os países do BRICS, nossos contactos científicos ampliem e aumentem o número de alunos que estudem ou façam estágios em universidades desses países. A Rússia oferece muitos projetos interessantes e frutíferos que possam ser úteis tanto para o desenvolvimento pessoal de estudantes quanto para o uso dos conhecimento e da experiência adquiridos em benefício de seus países.

\section{Referências}

AMIROVA, T. A. \& Ol'khovikov B. A. \& Rozhdestvenskiy YU. V. Istoriya yazykoznaniya.- Obrazovatel'no-izdatel'skiy tsentr "Akademiya", 2007, 672 p. [in Rus.].

BEREZIN, F.M. Istoriya russkogo yazykoznaniya. M.: Vysshaya shkola, 1979, 223 p. [in Rus.].

BEREZIN, F.M. Otechestvennyye lingvisty $X X$ veka. Moscow, 2003, 165 p. [in Rus.].

BERNARD, Comrie; STONE, Gerald; POLINSKY, Maria (1996). The Russian Language in the Twentieth Century, 2nd ed. Oxford: Oxford University Press, 1996. ISBN 9780198240662.

Dicionário Internacional da Arte, da Literatura e da Cultura Contemporânea da Lusofonia. Patrocínio CPLP; Cadernos do Povo / Revista Internacional da Lusofonia, Braga 2006115 p. 
KOLESOV, V.V. (2003) Istoriya russkogo yazykoznaniya. Sankt Peterburg, Izdvo SPb un-ta, 2003. 472 p. [in Rus.]

Mir Luzofonii. Materialy mezhdunarodnoy nauchnoy konferentsii. Izd-vo Sankt Peterburg 2001, 327 p.

SHULEZHKOVA, S.V. (2006). Istoriya lingvisticheskikh ucheniy. Moscow: Flinta, Nauka, 2006. 404 p. [in Rus.]

Uriel Weinreich Languages in contact: findings and problems (1964). The Hague: Mouton, 1964

Retrieved from: https://www.worldcat.org/title/languages-in-contactfindings-and-problems/oclc/4678953

VINOGRADOV, B. B. (2005). Istoriya russkikh lingvisticheskikh ucheniy. Moscow. Vysshaya shkola, 2005, 366 p. [in Rus.]

ZHARKOVA, T. I. (2014). Sovremennyye metody obucheniya inostrannomu yazyku // Gumanitarnyye nauki. Vestnik Finansovogo universiteta. 2014. №2 14, p. 69-72. Retreived from: https://cyberleninka.ru/article/n/sovremennyemetody-obucheniya-inostrannomu-yazyku

Recebido em 20 de novembro de 2020

Aceito em 15 de dezembro de 2020 